\title{
Contemplation, the Noble, and the Mean: The Standard of Moral Virtue in Aristotle's Ethics
}

Thomas M. Tuozzo

Aristotle appears to make the following claims about the end of morally virtuous action:

(1) Virtuous action is chosen for its own sake.

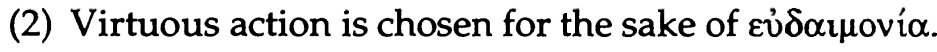

(3) Virtuous action is chosen for the sake of the noble.

(4) Virtuous action is chosen for the sake of contemplation. ${ }^{1}$

Understanding Aristotle's ethical theory requires understanding how these four characterizations of the end of virtuous action fit together. Much contemporary work on this subject proceeds as if these four claims could be reduced to two:

1 Texts giving prima facie evidence for these claims: (1) EN 1105a33; (2) EN 1097b2-5; (3) EN 1115b11-13, 1116a11-12, 1117a8, 1120a23-4, 1122b6-7, EE 1229a8, 1230a27; (4) EN 1145a6-11, 1177b1-15, EE 1249b6-23. 
(1) Virtuous action is chosen for its own sake.

(4) Virtuous action is chosen for the sake of contemplation.

This reduction is made by arguing that choosing something for its own sake just is choosing it for the sake of $\varepsilon \dot{\delta} \delta \alpha \mu$ oví $\alpha$, and by tacitly assuming that choosing something for its own sake is equivalent to choosing it for the sake of the noble. ${ }^{2}$ Concerning the remaining two claims, some scholars declare an inconsistency in Aristotle's ethical writings, while others, pointing to the fact that for Aristotle a thing may be chosen both for its own sake and for the sake of something else, argue that virtuous action (sometimes, often, or always) is chosen not only for its own sake but also for the sake of contemplation. Those taking the latter approach differ as to whether the ends of virtuous action and contemplation may ever conflict in Aristotle's view, and, if they do, how he thinks such conflicts should be decided. ${ }^{3}$

The family of interpretations described in the preceding paragraph agree in holding that virtuous action has a nature and worth independent of any relation it may have to contemplation, so that choosing it for its own sake does not entail choosing it for the sake of contemplation. The interpretation here proposed denies that claim; I shall argue that for Aristotle a complete account of the nature and value of virtuous action makes reference to contemplation, and that therefore choosing virtuous action for its own sake involves choosing it because of its relation to contemplation. ${ }^{4}$ Contemplation constitutes, in a sense

2 The equivalence of (1) and (2) is the underlying idea of the general family of interpretations known as 'inclusivism', the original representatives of which include Ackrill (1974/1980), Cooper (1975), Irwin (1978), Nussbaum (1986). In these earlier writings little attention is paid to the role of 'the noble' in Aristotle's theory. Irwin (1985), 127 makes noble goods a proper subset of intrinsically worthwhile goods, arguing, from a passage in Rhetoric 19, that noble goods are those intrinsically worthwhile goods which benefit others. Engberg-Pedersen (1983), 40 offers a similar interpretation of the noble, as does White (1992), 273 n.4. Rogers (1993) cogently rehearses the objections to such an interpretation.

3 The schema of possibilities is laid out by Keyt (1978).

4 In Aristotelian terms, one can say that the moral virtues stand, as goods, in a $\pi$ oos हैv relationship to the 'focal' good of contemplation. I should point out that it is not part of my view that the virtuous agent explicitly looks to contemplation as he decides how to act. He looks to the noble, which, however, gets its content from its relationship to contemplation. 
to be explained, an indirect standard for virtuous action. The connecting link between virtuous action's being chosen for its own sake (1) and its being chosen for the sake of contemplation (4) is provided by the notion of its being chosen for the sake of the noble (3). As Aristotle tells us at Metaphysics 1078a37-b1 (discussed below), the noble (beautiful, fine: $\tau$ ò $\kappa \alpha \lambda o ́ v$ ), in general consists in a certain determinateness, a determinateness that is presumably appropriate to the specific sort of thing that is to be $\kappa \alpha \lambda$ óv. That determinateness for the sake of which virtuous action is chosen is a certain determinate state of the soul, the value of which, I shall argue, is derived from its relation to contemplation. Furthermore, since virtuous action, in being chosen for the sake of the noble, is chosen for the sake, ultimately, of contemplation,

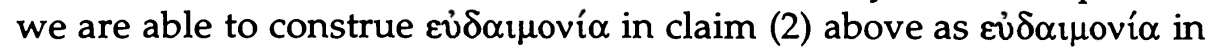
the primary sense, that is, as contemplation.

On this interpretation, then, all characteristically human activities, including those that are actualizations of moral virtue, derive their nature, in part, ${ }^{5}$ from their relation to the one highest human activity, contemplation. One of the advantages of this interpretation is that it brings Aristotle's theory of human activity into line with his metaphysics, according to which there should be some single, unitary activity, the active potentiality for which is the essence of a natural substance, and from which all other activities characteristic of that substance are in some way derived. Any interpretation which recognizes a plurality of distinct, (onto-)logically unrelated activities as together constituting the highest human good runs the risk of making Aristotelian ethics incompatible with the unity of substance central to Aristotelian metaphysics.

My argument will proceed as follows. First, I discuss the alleged independence of Aristotelian virtuous action from contemplation. The person of practical wisdom (i.e., the $\left.\varphi \rho o^{\prime} \iota \mu \circ\right)$ ), I argue, employs certain

5 This qualification is necessary because many human activities - perhaps all but contemplation - will be explained by reference both to the highest, essential human activity and to the constraints imposed by matter. In his biological works Aristotle emphasizes the need to take into account both formal and material factors in explaining the activities of natural substances; he designates these factors by the expressions 'the good' and 'the necessary'. See Parts of Animals I 1. For the relevance of material constraints in understanding the place of activities other than contemplation in human life, see Aristotle's brief remarks at EN 1154b20-31. 
general principles, each corresponding to one of the moral virtues, as the starting points for moral deliberation. These general principles are not mere rules of thumb (although they do hold only 'for the most part'); rather, it is a necessary condition of an action's being a virtuous action that it be in accordance with one such rule. Furthermore, I shall show that for Aristotle these general principles themselves require a standard that helps determine their content, and that Aristotle explicitly tells us that that standard is contemplation. After explaining how contemplation functions as that standard, I raise the question of the degree to which Aristotle's discussion of the particular moral virtues and vices coheres with what I have argued to be his general account of moral virtue. Lastly I consider the problem of how contemplation can serve as the moral standard for persons incapable of contemplation, and conclude with some more general reflections on the structure of Aristotle's ethical theory and its contemporary relevance.

\section{The Alleged Autonomy of Virtuous Action in Aristotle}

At EN 1113a29-33 Aristotle writes as follows:

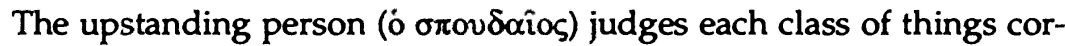
rectly, and in each what is true is apparent to him. For things that are noble and pleasant are peculiar to each state of character, and perhaps the upstanding person differs most [from others] in that he sees the true in each case, being as it were their yardstick and measure ( $\kappa \alpha v \grave{o v} \kappa \alpha i$ $\mu \varepsilon \dot{\tau}$ роv). ${ }^{6}$

I shall assume, as do most interpreters of Aristotle, that the judgment of the good or upstanding person does not in itself bestow nobility and pleasantness on things, but rather correctly discerns the things that are truly noble and pleasant independently of the good person's judgment. Now there are two possible views of the role of general rules in the good person's discernment of the noble and pleasant: either those rules do the

6 All translations are modifications, ranging from slight to extensive, of the revised Oxford translation: Barnes (1984). 
main evaluative work while deliberation, guided by a trained perceptual capacity, works out the upshot of those rules for the situation at hand; or such rules are mere rules of thumb, in principle dispensable, while the discerning of the noble takes place essentially at the level of particular perceptual judgment.

Many scholars hold that for Aristotle the discernment of value takes place at the level of particulars, with general rules serving only as rules of thumb. ${ }^{7}$ This interpretation, which derives some apparent support from Aristotle's position that general rules in ethics hold only 'for the

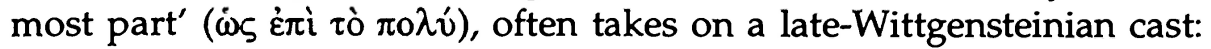
the possession of a concept need not involve possession of a rule or set of rules fully specifying its application - indeed, such specification is impossible - but rather is manifest in successful practice of a language-game in which that concept figures. ${ }^{8}$ Now such interpretations are right in stressing that for Aristotle there is no set of rules that fully specify the application of such moral concepts as 'courageous', 'temperate', etc. They are wrong, however, in holding that there are no principles corresponding to these moral terms that are prior to the particular moral actions which manifest them. The person of practical wisdom possesses certain general principles which he applies to particular circumstances. These principles neither fully specify their application - deliberative and perceptual ability play irreducible roles - nor are they mere rules of thumb. They give the essential starting points for all moral deliberation; possession of them is in part constitutive of being virtuous.

7 M. Nussbaum has been an influential defender of this view. See Nussbaum (1986): '[R]ules and universal principles are guidelines or rules of thumb: summaries of particular decisions, useful for purposes of economy and aids in identifying salient features of the particular case' (299); '[U]niversal statements are posterior in ethical value to concrete descriptions, universal rules to particular judgments' (301). Also see Nussbaum (1978), 210-19 and Louden (1986/1991), 163. Among philosophers in the continental tradition the most influential holder of this position has been Gadamer (1990), 312-24, recently followed by Dunne (1993).

8 The influence of the later Wittgenstein on this interpretation of Aristotle is made explicit by MacDowell (1979), 336-42. See also the Wittgensteinian coloring of Woods (1986), 160: '[Aristotle's] point is that, in this [i.e., in the practical] case, the universal is nothing over and above the particular instances, in that there is nothing more to grasping the universal than being able to identify instances of the specific sorts that comprise it ...' (emphasis in original). 
The defense of this interpretation may take its start from Aristotle's definition of moral virtue at EN 1106b36-7a2:

Virtue is a state concerned with choice, consisting in a mean state $(\dot{\varepsilon} v$

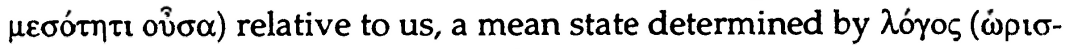

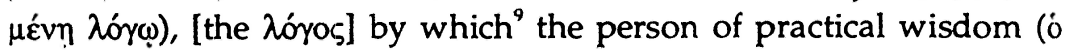

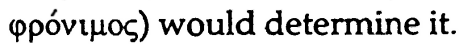

Should we translate $\lambda{ }^{\prime} \gamma \omega$ in this passage by 'reason', referring either to the rational faculty of the practically wise person or to its functioning (i.e., the process of reasoning), ${ }^{10}$ or should we translate by something like 'principle' or 'rule'?" ${ }^{11}$ Stocks pointed out long ago that the dative with $\dot{\omega} \rho \tau \sigma \mu \varepsilon v \eta n$ would be most naturally taken to refer to the standard or criterion by reference to which something is determined, and not to the agent, judge, psychic faculty, or process that performs the determination. ${ }^{12}$ Furthermore, as Stocks also pointed out, Aristotle seldom, if ever, in the ethical works uses $\lambda$ óyos to refer to a psychic capacity. There are, however, more substantive reasons to resist the translation of $\lambda$ ó $\gamma \omega$ here as 'reason', and, since this translation has recently found much favor, it is important to draw attention to them.

In the definition quoted above, virtue is said to be a state $\dot{\varepsilon} v \mu \varepsilon \sigma o ́ \tau \eta \tau \imath$ ovjo $\alpha$, that is, consisting in a mean state. This mean state must be distinguished from the intermediate ( $\tau$ ò $\mu$ ćoov) which is aimed at and chosen by the virtuous person when he or she acts: the former is the

9 Reading $\hat{\varphi}$. If one takes the other reading, $\dot{\omega} \zeta$, translate: 'in the way that...' Translating $\lambda$ ópos by 'reason' requires the reading is.

10 This is the translation adopted by Urmson in the revised Oxford translation, as well as by Irwin (1985b) in his translation; a similar view of the passage is shared by many contemporary writers. Earlier proponents of this view include Greenwood (1909), 166-7 and Cook-Wilson (1913).

11 This view is reflected in Ross's original Oxford translation, and is defended by Bumet (1914) and more fully by Joachim (1951) ad loc. Woods (1992) adopts the translation 'rule' for $\lambda$ óyos at EE 1249b4, where, as I shall argue, Aristotle is concerned to explicate the $\lambda$ ópos that figures in his definition of moral virtue.

12 Stocks (1914), 9: 'When the passive voice of opi $\zeta_{\varepsilon i v}$ is joined with a noun in the dative, that noun is never the defining faculty, or judge, or legislator, but rather the standard, or measure, or mark, by which the definition is effected...' 
psychic state that disposes one to seek the latter. ${ }^{13}$ If this is so, then there is strong reason to think that the $\lambda$ óyos referred to in the definition of virtue is not concerned with action in a particular situation. For what is determined by $\lambda$ ó ${ }^{\prime} \varsigma$ here is the mean state that courage, say, or temperance consists in; not what is courageous or temperate on a particular occasion. The belief that Aristotle is concerned with reasoning in particular circumstances in this passage is very widespread indeed among interpreters of the Ethics, ${ }^{14}$ and perhaps explains the tendency to take $\lambda$ óyo $\zeta$ to refer to the capacity to reason or the process of reasoning. But

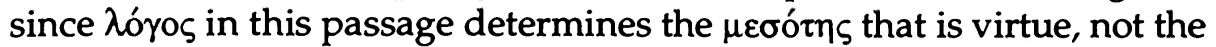
particular act that counts as the $\mu \varepsilon$ $\sigma o v$ in a particular situation, Aristotle

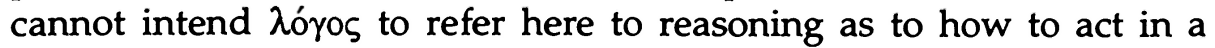
particular situation.

What, then, does $\lambda$ ó ${ }^{\circ} \varsigma$ refer to in the definition of moral virtue? First of all, we must realize that the definition is a general one that should apply to each of the moral virtues. Each moral virtue is a capacity to choose the intermediate in a certain sphere of human experience: ${ }^{15}$ eating, drinking and having sex; fighting in battle; engaging in business transactions; entertaining friends; etc. In each sphere the appropriate virtue makes one capable of performing an array of widely varying actions (e.g., attacking, retreating, standing ground in battle), all of

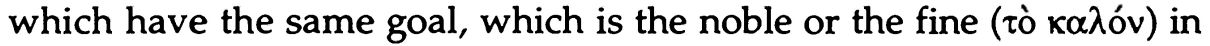
that sphere. The noble-in-battle is the general goal which different courageous actions aim to achieve in different particular circumstances. ${ }^{16}$ Indeed, it is the 'for-the-sake-of-which', the end ( $\left.\tau \dot{z} \lambda \circ \varsigma\right)$, of the virtue courage, as Aristotle tells us at EN 1115b11-13: '[The courageous person] will fear [things frightful for human beings], but he will endure

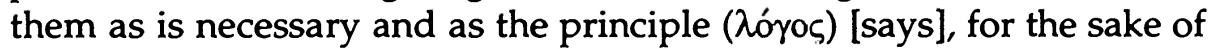

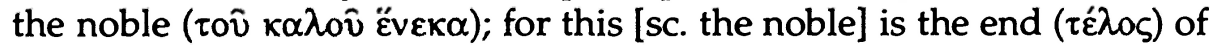
virtue.' This passage suggests the following more general interpretation:

13 See EN 1106b27-8: 'Virtue is a mean state, since it aims at the intermediate.'

14 See, for example, Rowe (1971), 111.

15 I adopt the notion of 'spheres of experience' from Nussbaum (1988), 35.

16 Thus the noble-in-battle is the intermediate which the courageous person aims at and, when particularized by deliberation, chooses. Cf. EN 1113a2-4: 'What is deliberated upon and what is chosen are the same thing, except that what is chosen is already determinate.' 
in the statement 'virtue consists in a mean state determined by $\lambda$ ó ${ }^{\circ} \varsigma^{\prime}$, $\lambda$ óyos refers in each case to a principle expressing the end specific to each particular virtue: namely, the noble in the relevant sphere of human life. Each virtue is an orientation of certain emotional and desiderative capacities towards the noble in some such sphere, an orientation expressible by a $\lambda$ ó ${ }^{\prime} \varsigma$ enjoining action for the sake of the noble-in-that-sphere. Furthermore, virtue is not just a desiderative orientation expressible by a $\lambda$ ó ${ }^{\circ}$; it is a desiderative orientation that brings with it a conscious awareness of that $\lambda{ }^{\prime} \gamma o \zeta$, which the agent may use as the first premise of his deliberation in situations requiring deliberation. ${ }^{17}$

The general principles stating the ends of the various moral virtues, then, play an important role in Aristotle's ethical theory. What are they, and why does Aristotle never give us a clear statement of them? Given the foregoing discussion, it is fairly easy to formulate these general principles. They are to state the end or goal to be attained in each of the spheres corresponding to the moral virtues. Now the end in a sense always stays the same, namely, the noble; what changes is the sphere of experience in which that end is pursued. Accordingly we may frame the first principles of the Aristotelian virtues as follows:

Courage: Endure life-threatening battle conditions for the sake of the noble.

Temperance: Satisfy desires for food and sex for the sake of the noble.

Liberality: Spend your wealth on others for the sake of the noble.

Etc.

If moral first principles take this form, then it is understandable that Aristotle does not present us with a list of them; it is a trivial matter to extract them from his discussions of the various moral virtues, which specify both the end of the virtues (the noble) and the specific arenas of the different virtues. It may be objected that these principles are empty, absent any account of what the noble consists in; indeed, they seem to derive their susceptibility to this criticism from the discussions from

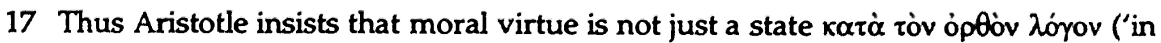
accordance with the correct principle', EN 1103b32, 1144b23), but rather a state $\mu \varepsilon \tau \dot{\alpha}$

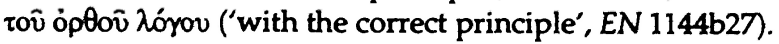


which they are extracted, which have sometimes been thought to require a more substantial account of the noble than Aristotle there gives us. ${ }^{18}$ It is certainly going too far to say that Aristotle's discussions of the moral virtues are empty, but it is true that they, and the principles I have drawn from them, leave a gap which only an account of the noble can fill. Indeed, Aristotle explicitly acknowledges this in EN VI 1, and provides the requisite account of the noble in EE VIII 3 . These passages are discussed in the next section. I shall close this section by showing how moral first principles, as conceived above, may be prior to judgments about particular moral actions while nevertheless holding only 'for the most part'.

If moral first principles have the form suggested, then it will be possible for a particular situation to fall under more than one principle. A certain situation (e.g., receiving an inheritance) may seem to be an occasion to act liberally (entertaining friends) as well as an occasion to act justly (repaying a debt). The person of practical wisdom will be capable of perceiving which virtue is called for in that situation, ${ }^{19}$ and will accordingly deliberate from the correct moral principle. ${ }^{20}$ Moral principles are said to hold 'for the most part' because it is true for any one of them that sometimes, though it could be followed, it should not be. The rules themselves are not to blame (see EN 1137b17-19); indeed, they are indispensable, for they articulate the various kinds of value to which the person of practical wisdom is committed. Rather, the nature of practical human life is simply such that it sometimes confronts us with situations where more than one of these principles could apply.

18 Ross (1949), 204-5 complains that Aristotle never relates his belief that virtuous action is for the sake of the noble to his 'formal theory'.

19 A form of perception is necessary because there is, for Aristotle, no absolute priority of the concerns of one virtue over those of another.

20 He may discover that one moral principle is the correct one to act on in the course of deliberating from another. For a subtle discussion of this aspect of Aristotelian deliberation, see Broadie (1991) 232-60. 


\section{Nicomachean Ethics VI 1}

Aristotle opens book VI with an indication that the accounts of the various moral virtues in the preceding books were in some way incomplete. We may divide the chapter for our purposes into two parts.

The first section of the chapter reads as follows:

Since we have already said that one ought to choose what is intermediate, not the excess nor the defect, and that the intermediate is as the correct principle ( $\lambda$ ó ${ }^{\prime} \varsigma$ ) tells us, let us discuss this. For in all the states we have mentioned, as also in the case of the rest, there is some mark ( $\sigma$ Koлós) to which the person who possesses the principle ( $\lambda$ óyov) looks as he heightens and relaxes his efforts, and there is some standard (öpos) of the mean states ( $\mu \varepsilon \sigma 0 \tau \dot{\tau} \tau \omega v)$, which we say are in between excess and defect, since they are in accordance with the correct principle ( $\lambda$ óyov). (1138b18-25)

If by $\lambda$ ó ${ }^{\circ} \varsigma$ in this passage Aristotle means (general) principle, as I think he must, ${ }^{21}$ then Aristotle's point is that, insofar as a person of practical wisdom possesses (and uses) such a principle, he aims at some determi-

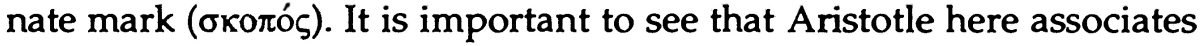
this mark with the state, which suggests that the $\lambda$ óyo $\zeta$ which states the 'mark' or aim is a general one and states the goal or end of the virtue. So, too, Aristotle tells us that there is a standard of the mean states ( $\mu \varepsilon \sigma o \tau \eta \dot{\tau} \omega v)$. This standard, then, is general, too; it is, indeed, the same thing as the mark or goal of virtue. As we have seen, the end of each virtue is the noble in the relevant sphere of experience, and the end of moral virtue in general is the noble sans phrase. Now in his discussion of the particular virtues, and in his preliminary account of moral virtue in general, Aristotle had argued that virtue disposes one to choose the

21 We must not suppose, on the grounds that the correct $\lambda$ ópos tells us the intermediate and the intermediate is what is chosen, i.e., a particular action, that $\lambda$ ójos here refers to the process of reasoning which determines the particular response. Since the major premise in a practical syllogism is the evaluative one, Aristotle not uncommonly says that it is this that 'tells us' the evaluative conclusion. Thus at EN 1147a34

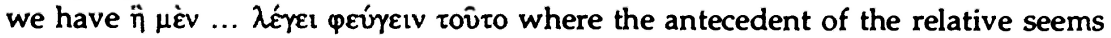

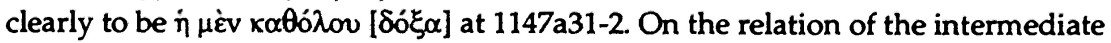
as general (at the beginning of deliberation) and as particular (at the end of deliberation), see note 16 above. 
intermediate action (and to feel the intermediate feeling) in the relevant sphere of human life. Thus intermediacy is a partial explication of the general goal towards which the virtues orient us in their respective spheres. In itself, however, the notion of the intermediate does not provide sufficient content to the noble for it to serve as a mark or aim of action and feeling, as Aristotle points out in the second half of our chapter.

The rest of the chapter runs as follows:

But such a statement, though true, is by no means clear. For not only here but in all other pursuits of which there is a science (i் $\pi 1 \sigma \tau \eta \eta \eta)$, it is indeed true to say that we must not exert ourselves nor relax our efforts too much or too little, but to an intermediate extent ( $\tau \dot{\alpha} \mu \varepsilon \dot{\varepsilon} \sigma \alpha)$ and as the correct principle ( $\lambda$ ó $0_{\varsigma}$ ) tells us. But if one only had this, one would be none the wiser; for example, one would be none the wiser about what sorts of things should be administered to the body, if someone were to say, "all that the medical art bids us, and as the person who possesses it directs." Therefore it is necessary with regard to the states of the soul also, not only that this true statement should be made, but also that it should be determined ( $\delta 1 \omega p r \sigma \mu \varepsilon \dot{v} o v)$ what the correct principle is and what is its standard (öpos). (1138b25-34)

Aristotle here emphasizes that for the principles of the virtues to direct our conduct, there must be some standard which determines what the noble is in the various fields of human life. That is, there must be some standard which supplies content to the nobility referred to in the general principles that define the virtues.

Aristotle is not looking for a standard for applying moral principles to particular circumstances. This point must stressed, since some commentators suppose that Aristotle here is merely calling attention to the fact that general principles of any sort cannot successfully be applied in practice without a trained judgment that is responsive to particulars. ${ }^{2}$

22 So, for example, Rowe (1971), 111. Broadie (1991), on the other hand, sees that this passage is concerned with the general specification of the goal of virtuous action, not with its application to particular circumstances. She rejects, however, any role for rules and general principles, maintaining that the general specification Aristotle here calls for is simply a description of the person of practical wisdom whom we may then seek to emulate (185-90). See 191: '[I]n the end, EN VI aims to present the фpóviuos as an archetype of the sort of person to try to be.' 
The use of medicine as an example may seem to corroborate such a reading, since medicine is one of the arts that Aristotle elsewhere stresses involve more deliberative attention to particular circumstance than other, more precise arts (compare EN 1104a5-10, 1112b2-8, EE 1247a5-7). But this cannot be the point of the medical example here. Aristotle tells us that his point holds good for 'all pursuits of which there is a science'; we must suppose that he could equally have used one of the more precise arts to make his point. This he could have done, if his point is that there must be some standard to give determinate content to the general principles of any practical or productive science. Nothing would have been lost if he had written, for example: 'One would be none the wiser about what sorts of things to do to build a house, if someone were to say, "all that the housebuilding art bids, and as the possessor of it directs". ${ }^{23}$ Knowing who it is who knows how to build a house is not the same as knowing how to build a house. Aristotle's point in this chapter is that the incompleteness in moral first principles introduced by their reference to nobility or intermediacy cannot be compensated by referring (as was done, as a stop-gap, in the definition of moral virtue in EN II 6) to the knowledge possessed by the one who possesses those principles. For it is in virtue of possessing those principles that the virtuous person has the (universal) knowledge ${ }^{24}$ he does; no amount of dexterity in applying them can supply them the content that Aristotle here recognizes they (at this point in the investigation) lack.

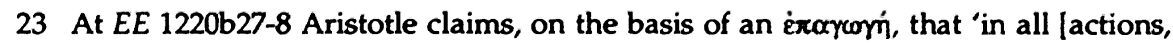
scientific as well as non-scientific], the intermediate relative to us is what is best;

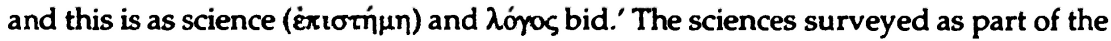

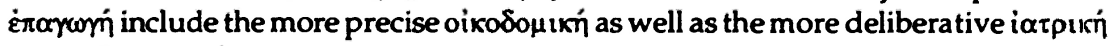

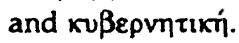

24 That there is a universal component to practical wisdom, distinct from the crucial ability to apply these universals to particular circumstances, is clear from $E N$ VI 1141 b14-15, where Aristotle writes: 'Nor is practical wisdom concerned with universals only, but it is necessary also to recognize particulars.' So, too, practical wisdom in its political employment as $\pi 0 \lambda \iota \tau \iota x \eta ́$ is divided into a universal component (

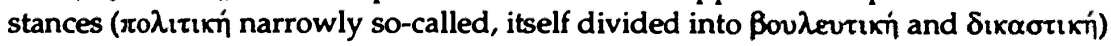
(1141b23-33). Shiner (1979), 381-3 stresses the importance of universal 'for the most part' truths for moral deliberation. 


\section{The Standard of Moral First Principles: EE VIII 3}

As is well known, Aristotle does not, in the course of EN VI, unambiguously provide us with the standard that the first chapter of that book shows moral first principles to require. ${ }^{25}$ At the end of $E E$ VIII 3, however, Aristotle raises the same question he raises in EN VI $1,{ }^{26}$ and proceeds to identify the sought-for standard. The passage in question begins as follows:

Now since there is a certain standard (öpos) for the doctor, by reference to which he judges what is healthy for a body ${ }^{27}$ and what is not, and with reference to which each thing is to be done up to a certain point, and if it is done well, it is healthy, but if it is done more or less, it is so no longer, so too for the virtuous person, in connection with actions and choices of the things naturally good but not choiceworthy, there must be some standard (öpov) of the possession, choice, and avoidance of greatness and littleness ${ }^{23}$ of wealth and of the gifts of fortune. Now in what went before, the answer was given: "as the principle ( $\lambda$ ó ${ }^{\circ} \varsigma$ ) says"; but this is as if one were to say, in regard to diet, "as the medical art and its principle ( $\lambda$ ó ${ }^{\circ}$ ) say." This, though true, is not clear. (1249a21-b6)

As in EN VI 1, so here, in both the practical and the medical cases the knowledgeable person approaches the particular case with a general

25 A brief passage at the end of EN VI does, in my opinion, give the required standard (1145a6-11). Its brevity makes its interpretation especially open to question, however, so it is methodologically sounder to discuss first the more explicit discussion of the standard in EE VIII 3.

26 Many writers think that, despite the manifest similarities to $E N$ VI 1, Aristotle in $E E$ VIII 3 is concerned not with moral choices, but with some other sort of choices. So Ackrill, (1974/1980), 30-1; Broadie (1991), 384-5; Cooper (1978), 135-43; Kraut (1989), 169-70; and Rowe (1971), 110. The untenability of such an interpretation has been shown by Kenny (1978), 182-3, who points out that virtuous action consists precisely in using external and bodily goods (= things naturally good) in the best possible way, and that EE VIII 3 is concerned with providing the standard for such use.

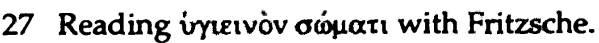

28 The normative implications of Urmson's 'excess or deficiency' here (Barnes [1984]) are out of place, Aristotle never to my knowledge uses $\pi \lambda \hat{\eta} \theta 0 \varsigma$ for $\dot{u} \pi \varepsilon \rho \beta 0 \lambda \dot{\eta}$, nor

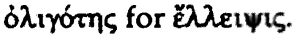


principle ( $\lambda$ ó $0 \varsigma$ ) which states the standard (öpos) he will use in deliberating how to act. Here, too, it is suggested that the principle enjoins one to act in some intermediate way - not too much, not too little - but it is equally clear that this explication of the standard does not go far enough, and that a further determination of its nature is possible and needed. Later on in this chapter Aristotle attempts to meet this need. Indeed, he gives us two distinct formulations of the standard, each of which, as we shall see, contains material essential for the correct understanding of Aristotle's position.

The two formulations Aristotle gives of the standard are as follows:

(I) Whatever choice and possession of naturally good things most produces the contemplation of $\operatorname{god}^{29} \ldots$, that is best, and this is the noblest standard (otน (1249b16-19)

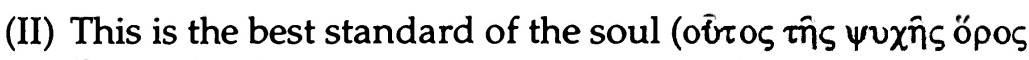

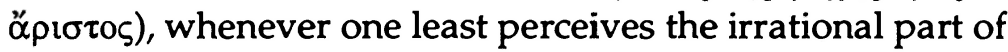
the soul, as such. (1249b21-3)

These formulations differ in two ways: (a) (I) presents itself as the standard of the 'choice and possession of naturally good things', while (II) presents itself as the standard of 'the soul'; and (b) (I) specifies the standard as 'the contemplation of god', while (II) specifies it as 'least perceiving the irrational part of the soul, as such'. If we grant that together these formulations are meant to give the standard of moral virtue as a whole, as the end of the chapter clearly states, ${ }^{30}$ then we might account for (a) by supposing that (I) gives the standard for the virtues concerned with 'naturally good things': magnanimity, magnificence, liberality; while (II) gives the standard for the virtues concerned with the passions of the irrational soul: courage, temperance, gentleness of temper. ${ }^{31}$ Such a division between 'outer' and 'inner' virtues, how-

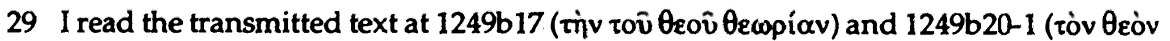

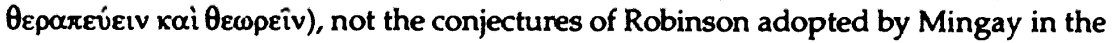
recent OCT.

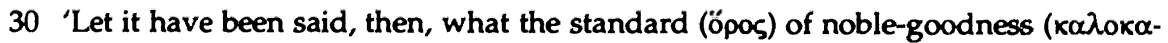

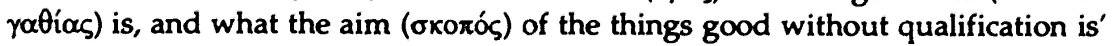
(1249b23-5).

31 This is the interpretation of Kenny (1978), 183. 
ever, is attested nowhere else in Aristotle, and seems to me fundamentally unaristotelian. For Aristotle, every moral virtue is concerned with 'feelings and actions', ${ }^{32}$ the paradigmatic activity of moral virtue is the choice as to how to use some external or bodily good to achieve the noble, a choice which, as an ö $\rho \varepsilon \xi_{1 \zeta}$, has an affective dimension and counts as a $\pi \alpha \dot{\theta} \theta{ }^{3} .{ }^{33}$ It is more plausible, then, to suppose that these two formulations refer to the 'inner' and 'outer' aspect of each of the moral virtues.

Both actions and feelings admit of excess, deficiency, and the intermediate amount; it is reasonable to suppose that we could formulate the standard of the virtuous mean in two ways, one with respect to feelings, the other with respect to actions. However, if these two formulations apply to the same virtues, then they must dictate, in particular cases, actions and feelings appropriate to one another. To put it another way: they must determine the affective and the external aspects of the very same action. Thus we are led to consider (b): the difference in the content of the standard offered in the two formulations quoted above. (I) tells us that we should choose and keep naturally good things in such a way as best to promote the contemplation of god; (II) tells us that we should least perceive the irrational part of the soul, as such. Since these are alternative formulations of the same standard, we may conclude that the feelings that enable us least to perceive the irrational part of the soul as such are those that accompany the dealings with external and bodily goods that best promote the contemplation of god.

Now to say that certain feelings enable us least to perceive the irrational part of the soul as such is to say something like: these feelings are the least irrational we could have. This notion in itself is hardly perspicuous; our only clue to its meaning is that the actions of which these feelings are a part best promote the contemplation of god. I suggest, then, that these feelings count as least irrational because they least prevent one from engaging in the contemplation of god. What makes certain uses of naturally good things virtuous is that the feelings that motivate and accompany them are such as least to impede the exercise of theoretical

32 See EN 1106b24-5: '[Moral] virtue is concerned with feelings and actions ( $\pi \varepsilon \rho i$ ió $\theta$ n

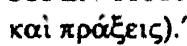

33 For further discussion of the affective aspects of moral choice, see Tuozzo (1994). 
wisdom. On this interpretation, the virtues derive their value from being the developed states that produce such feelings and such actions. ${ }^{34}$

The claim that certain $\pi \alpha \dot{\theta} \theta$ may impede contemplation more than others, and that the psychic states that produce the former are the moral virtues, stands in need of further explication, to which I shall turn shortly. First, however, I should like to point out that my interpretation of the way in which theoretical contemplation may be a standard for the moral virtues escapes an objection normally raised against such interpretations. It is said that, if contemplation is made the standard of virtuous action, then whatever action in a particular situation best promotes the conditions of contemplation is the morally virtuous one. It would seem to follow that if a theft would enable an otherwise destitute philosopher to live a life of contemplative leisure, that theft has a good claim to being the morally virtuous action in these circumstances. Such an absurdity would follow, however, only if the way in which an action promoted contemplation was irrelevant. On the current interpretation, what must be considered is the effect of the feelings or $\pi \alpha \dot{\theta} \eta$ associated with an action on the possibility of contemplation. We might put the standard, as I understand it, in the following terms: that action which best promotes the internal, psychic conditions of theoretical contemplation is the morally virtuous action. The fact that an action will procure the money, the time, or anything else from among what may be termed the 'external conditions' of contemplative activity is irrelevant to its moral worth.

What are the psychic conditions of contemplation, and how can the $\pi \alpha \dot{\theta} \theta \eta$ associated with $\pi \rho \hat{\alpha} \xi_{\llcorner\varsigma}$ promote or impede those conditions? Aristotle gives us no answer to this question in $E E$ VIII 3, but an important clue can be found in a passage in the Magna Moralia, a work that almost all scholars agree is based on an Aristotelian lecture course in ethics, whether it was substantially written by Aristotle himself or by a pupil. ${ }^{35}$ The Magna Moralia describes the relationship between $\varphi p o ́ v \eta \sigma i s$ and бo甲í $\alpha$ as follows:

34 One benefit of my interpretation is that it gives a good sense to a phrase in EE VIII 3 that has resisted understanding and so prompted editors and translators from Ross to Woods to resort to emendation. See appendix.

35 For two discussions of this question, and references to further discussion, see Cooper (1973) and Kenny (1978), 216-20. 


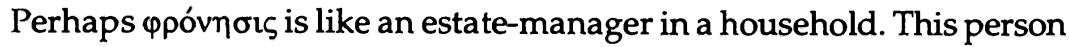
has authority over everything and manages everything; but he does not for all that rule over everything, but provides leisure ( $\sigma \chi 0 \lambda \eta \dot{v})$ to the master, so that the latter may not, hindered by necessities, be prevented from doing some noble and fitting thing. In this way and similarly to

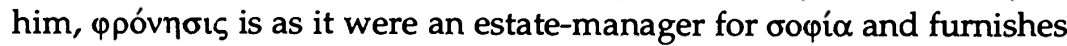
it with leisure ( $\left.\sigma \chi 0 \lambda \eta^{\prime} v\right)$ and the chance to perform its own work, by restraining the passions $(\pi \alpha \dot{\theta} \eta)$ and making them temperate

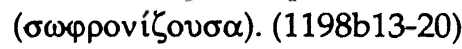

What this passage adds to the account in EE VIII 3 is the notion of a certain leisure for contemplation, provided by $\varphi$ óvnois through its control of the passions in virtuous action. ${ }^{36}$ Now since it is presumably impossible both to contemplate and to act morally (or immorally) at the same time, the leisure in question must be leisure from action in general. Since all action is prompted, and accompanied, by $\pi \alpha$ ón of some kind (óp $\xi_{1 \varsigma}$ being here included), it would seem that virtuous action promotes contemplation by effecting an absence of action-oriented passion. It does so, I suggest, by fully exhausting, as it were, the $\pi \alpha \dot{\theta} \eta$ connected with it. Actions proceeding from a vicious character, on this view, will tend to leave some passionate residue in the agent - unsatisfied appetite, regret, etc. - which pushes the agent to action once again. Virtuous action will not leave such residue: the affective component of the action is exhausted in the action, without producing any further affect that impels one to act further. Virtuous actions are thus what we may call 'affectively complete', and result in the psychic leisure from actionprompting affect required for contemplation.

The affective completeness of virtuous actions reflects, I suggest, their more fundamental metaphysical completeness. The moral virtues are perfections or completions of our essential potentialities to feel and act (cf. Physics 247a2). Their actualizations, virtuous actions, will accordingly also be complete. In the terms Aristotle uses in Metaphysics $\theta$ 6,

36 It has been suggested that the role here ascribed to $\varphi$ póvnois either is quite distinct from its role in virtuous action, or is only part of its role in virtuous action. The use of the term owppovi ${ }_{0} \sigma \sigma \alpha$, however, strongly suggests that the role here described is a moral one, and the comparison with the estate-manager suggests that it is its sole function. 


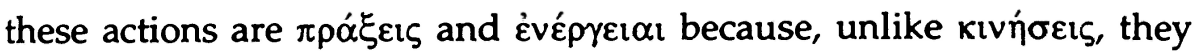
contain their own ends within themselves (1048b22-3). On the interpre-

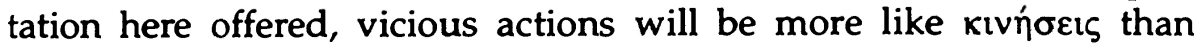

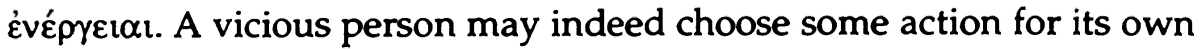
sake, but the $\pi \alpha \theta_{\eta}$ that motivate and accompany the action will not find adequate expression in that action. In some form or other a psychic residue will remain, such that the agent is directed toward further action. ${ }^{37}$ If this is so, then there is a relatively straightforward sense in which we may use Aristotle's account of the noble in Metaphysics M to give content to the claim that virtuous action is chosen for the sake of the noble. At Metaphysics 1078a37-b1 Aristotle writes, 'The three forms ( $\varepsilon_{i \prime}^{\prime} \delta$ )

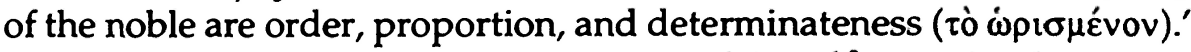
The self-containedness and completeness of the $\pi \alpha \theta_{\eta}$ involved in virtuous actions reflects their metaphysical determinateness, which is the ultimate ground of their nobility.

\section{Psychic Leisure and Particular Moral Virtues}

The above account has emerged from an investigation into the more theoretical passages in Aristotle's work concerning the nature of moral virtue. It is an open question whether Aristotle's discussions of the particular moral virtues will prove in every respect consistent with this account; Aristotle's sensitive exploration of the right ways of feeling and acting in different spheres of human life may well produce results in tension with his official account of their relation to primary $\varepsilon \dot{\delta} \delta \alpha \mu \nu$ oví $\alpha$. Indeed, I suspect that this is the case. Nonetheless, I believe that Aristotle's discussion of a number of virtues and vices can be seen to conform to the general account of virtue offered here, and that, furthermore, it is plausible to suppose that Aristotle felt that the investigation of the virtues from starting points provided by moral experience would ulti-

37 Garver (1989) offers an interpretation along somewhat the same lines: 'Virtuous actions are the only ívépreı $\alpha$ of the irrational but persuadable part of the soul that fit Aristotle's sense of complete évépreı $\alpha$ in the Metaphysics, غ̇vépreı $\alpha$ as opposed to incomplete kivno's' (303). Garver, however, holds that vicious actions are incomplete in the sense of being in some sense indeterminate or arbitrary (see 303-4), while I hold that they are incomplete in the sense of prompting the agent on to further action. 
mately prove consistent with his account of their relationship to contemplation. In this section I shall show how at least some of Aristotle's accounts of particular virtues and vices can be seen to conform to his general account of virtue.

The easiest case is perhaps that of self-indulgence ( $\dot{\alpha} \kappa \circ \lambda \alpha \sigma i \alpha)$. The self-indulgent person values certain bodily pleasures 'more than they are worth' (EN 1119a19-20); indeed, he holds that the more of them he gets, the better, as the following passage indicates:

If, then, [the part of the soul that desires pleasure] is not going to be obedient and subject to the ruling part of the soul, it shall increase; for in a thoughtless thing the desire for what is pleasant is insatiable and draws gratification from any place it can, and the activity of appetite increases its natural force. (EN 1119b7-9)

The experience of bodily pleasure does not satisfy the desire of the self-indulgent person, who must always be concerned to procure more such pleasure, else feel the pain of unsatisfied desire (cf. EN 1119a3-5).

Two other vices that seem to have the same structure as self-indulgence are prodigality ( $\dot{\alpha} \sigma \omega \tau i \dot{\alpha})$ and illiberality ( $\dot{\alpha} v \varepsilon \lambda \varepsilon v \theta \varepsilon \rho i \alpha)$. Prodigal persons 'have an appetite for giving' (EN 1121b2), and in their need to satisfy this appetite most of them do not scruple to acquire the necessary funds from any source possible, no matter how ignoble. Their desire to give is not fully satisfied by any particular act of giving, but remains to drive them on to further, indiscriminate largesse. So, too, all three types of illiberal person distinguished by Aristotle have one feature in com-

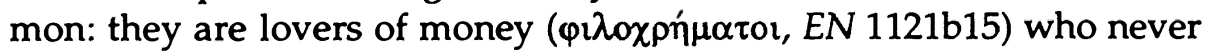
think that they have enough.

A vice with a somewhat more complex structure is rashness. 'Rash

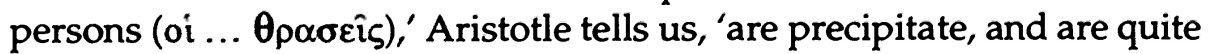
willing before dangers, but draw back when they are in them, while brave persons are keen in their deeds, but calm beforehand' (EN 1116a79). The brave feel the appropriate $\pi \alpha \theta_{0}$ s at the time of action, but feel no $\pi \alpha \dot{\alpha} 0 \varsigma$ beforehand, nor, we may assume, afterwards. The rash, however, feel confidence before battle, but during battle experience overwhelming fear. This change of $\pi \dot{\alpha} \theta 0 \varsigma$ thwarts the original $\pi \dot{\alpha} \theta 0 \varsigma$, which remains unfulfilled. The desire to be bold in danger reasserts itself when the danger is past, so that the rash person, as such, continues to feel an impetus to seek out dangerous situations in which to be bold. 
The vice of 'insensibility' ( $\alpha \dot{v} \alpha \iota \sigma_{\eta} \sigma^{\prime} \alpha$ ) is perhaps the most difficult to understand in terms of Aristotle's general account of virtue and vice. Insensible persons 'delight less than is right' in bodily pleasures ( $E N$ $1119 \mathrm{a} 6)$; in what way can they be held to be caught up in a chain of $\pi \alpha \dot{\theta}$ n that never gives them psychic leisure? '[S]uch insensibility,' Aristotle says 'is not human; for even the other animals discriminate among their foodstuffs, and rejoice in some and not in others; and if nothing is pleasant to someone and one thing is the same as another to him, he would be far from being a human being' (EN 1119a6-10). The insensible person is here depicted as someone who finds nothing pleasant. His inevitable physical desires, therefore, he must experience as mere pain, and the satisfaction of them as in some way merely relief from pain. If Aristotle holds that such a treatment of physical desires will not in fact do justice to them, so that the insensible man continues to feel an indefinite urge, in spite of himself, to satisfy them more fully, then this vice, too, can be seen to conform to the general account of virtue as providing the psychic leisure necessary for contemplation.

\section{A Problem}

There is another obvious objection to my account of the relation of contemplation to the moral virtues that must be addressed. Aristotle clearly supposes that contemplation requires intellectual gifts that many persons perfectly capable of moral virtue lack. How can, and why should, an activity which these persons can never perform serve as the standard - even an indirect standard - for their practical dispositions? This question is, I suggest, in some respects ill-conceived. It supposes that, on the interpretation here offered, the moral virtues are valuable merely instrumentally, insofar as they help bring about contemplation. Having no value in themselves, they would be pointless if one did not have the intellectual prerequisites for theoretical activity. Such a view overlooks the fact that morally virtuous activity is the excellent actualization of human capacities, and is as such intrinsically valuable, whether the contemplation which serves as its standard ever occurs or not. ${ }^{38}$

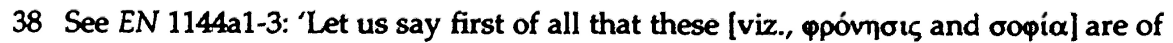
necessity choiceworthy in themselves, since each is the virtue of one part [sc. of the rational faculty], even if neither of them produces anything.' 
Contemplation determines what counts as the best states of the irrational part of the soul of all human beings, whatever their individual skills at theory.

A question may still seem to arise for the case of the morally virtuous person who is incapable of contemplation. The moral virtues are those states that enable one 'least to perceive the irrational part of the soul, as such.' Such a condition frees those capable of contemplation from domination by their $\pi \alpha \dot{\theta} \eta \eta$ and thus gives them the psychic freedom to contemplate. How do those incapable of contemplation use this psychic freedom? Such persons should play an active role in politics. Political life will enable them to exercise their practical wisdom and moral virtues on a grander scale, and since such activity is the highest of which they are capable, their lives are better to the extent that they engage in greater practical projects. And in those projects contemplation will continue to serve as an indirect standard. The politician's central aim is to make the citizens virtuous: ${ }^{39}$ that is, to produce in them the interior psychic conditions for contemplation. (He is concerned with the safety and prosperity of the city derivatively, as the material conditions of virtue.) Those citizens who are capable of contemplation will (in the ideal case) become philosophers; those who are not will in their turn become politicians.

\section{Conclusion}

Aristotle, then, provides a non-moral foundation for morality. He does so not by making moral action a matter of directly maximizing some non-moral good, but rather by holding that moral action gets its worth from promoting a certain inner state of the agent that is a necessary pre-condition of fully engaging in a non-moral activity of supreme worth: theoretical contemplation. ${ }^{40}$ Each of the moral virtues is a disposition towards noble actions in a particular sphere of human experience,

39 See EN 1102a7-10: The true politician seems to have labored most in connection with this [sc. virtuel; for he wishes to make the citizens good and obedient to the laws.'

40 The paradox that in Aristotle's theory of the good something may derive its intrinsic value from something else is addressed in Tuozzo (1995). 
and this commitment is expressible in a general rule that serves as the starting point for deliberation concerned with acting in that sphere. Noble actions in each sphere do not exemplify some primitive value, but rather derive their value from being the actions that fully exhaust their passionate components and so effect the psychic leisure that is the pre-condition for contemplation.

This is the account of virtue that emerges from following out Aristotle's more theoretical remarks on the nature and value of virtue. But we have seen that Aristotle's sensitive examination of the world of moral experience leads to accounts of the particular virtues that are in a degree of tension with this more theoretical account. Given the somewhat questionable nature of both Aristotle's insistence on the metaphysical unity of human beings and his view that theoretical contemplation is the human activity of highest worth, it is perhaps understandable that contemporary ethicists influenced by Aristotle emphasise his recognition of the richness of moral life and his notion of virtue as a receptivity to value (and a disposition to effect it) in the many spheres of experience, while ignoring the foundation of Aristotelian moral virtue in its relation to contemplation. Nonetheless, we must not make the mistake of supposing that the connection to contemplation is a merely external feature of Aristotle's ethics. It is Aristotle's sole and unrepudiated account of the source of the value of moral virtue and virtuous actions. Any ethics that rejects it must produce an alternative theory to undergird the insights into moral experience it may borrow from Aristotle. ${ }^{11}$

41 I would like to thank Roger Shiner for the helpful criticisms and comments he gave me on an earlier version of this paper, and Janet Sisson for her helpful comments on the penultimate version. Their comments have helped make this paper better than it was, though it still may not convince them. 


\section{Appendix}

At the beginning of his argument in EE VIII 3 for the two formulations of the standard discussed in section III above, Aristotle writes: 'Certainly it is necessary, as in other cases, too, to live with reference to the ruling element, and with reference to the state in accordance with the activity

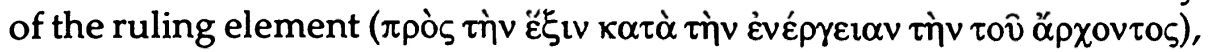
as the slave does with reference to that of the master' (1249b7-9). The obscurity of the phrase 'state in accordance with the activity' has led recent editors and translators to adopt Ross's emendation of $\kappa \alpha \tau \alpha$ to $\kappa \alpha i$, producing 'one must ... live ... with reference to the state and the activity of the ruling element. ${ }^{42}$ But the transmitted text is apt as it stands. It is not directly from the activity of contemplation that the moral virtues derive any of their content, but rather from 'the state in accordance with that activity', the state in which the potentially irrational passions of the soul do not deflect us from theoretical activity. ${ }^{43}$ Similarly, the slave does not derive the content of his best condition and work directly from the nature of the master's occupation, e.g., political activity. ${ }^{44}$ Rather the slave's work derives its content from the state which the master must find himself in if he is to be able to engage in his rightful occupation: a state free from the impediments to that occupation arising from the need to provide for the necessities of life for himself and his household. Slaves and moral virtue are, in Aristotle's thought, enabling conditions for the relevant activities they support, not collaborators in them.

42 Ross (apud Solomon's original Oxford translation, footnote ad loc.), retained in the revised Oxford translation, and followed by Dirlmeier (1963), Mingay (1991), and Woods (1992).

43 Verdenius (1971), 285-97, followed by Decarie (1978), $224 \mathrm{n}$. 92, retains the transmitted text, but gives it a sense opposite to mine, viz., 'with reference to the active state

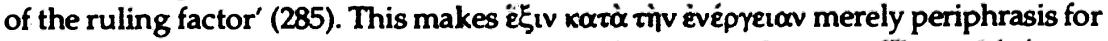

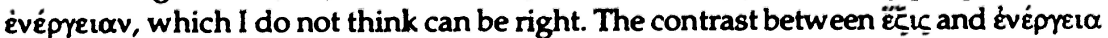
is crucial here, just as it is in EN 1122b1, which, though cited by Verdenius (1971), 287, does not seem to support his point.

44 Or philosophic activity, as the case may be; see Politics $1255 \mathrm{~b} 35-7$. 


\section{References}

Ackrill, J.L. 'Aristotle on Eudaimonia', Proceedings of the British Academy 60 (1974) 339-59; reprinted in A. Rorty, ed., Essays on Aristotle's Ethics. Berkeley: University of California Press 1980, 15-33. Cited from reprint.

Barnes, Jonathan. The Complete Works of Aristotle. The Revised Oxford Translation. Princeton: Princeton University Press 1984.

Broadie, Sarah. Ethics with Aristotle. New York: Oxford University Press 1991.

Burnet, John, ed. The Ethics of Aristotle. London: Methuen 1900.

Burnet, John. 'On the Meaning of גópos in Aristotle's Ethics', Classical Review 28 (1914) 6-7.

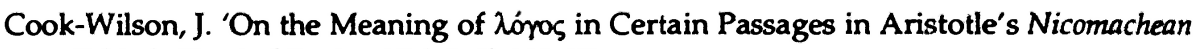
Ethics', Classical Review 27 (1913) 113-17.

Cooper, John M. 'The Magna Moralia and Aristotle's Moral Philosophy' American Joumal of Philosophy 94 (1973).

Cooper, John M. Reason and Human Good in Aristotle. Cambridge, MA: Harvard University Press 1975.

Décarie, V., tr. Aristote. Éthique d̀ Eudème. Paris: J. Vrin 1978.

Dirlmeier, Franz. Eudemische Ethik. Berlin: Akademie Verlag 1963.

Dunne, Joseph. Back to the Rough Ground: 'Phronésis' and 'Techne' in Modern Philosophy and Aristotle. Notre Dame: Notre Dame University Press 1993.

Engberg-Pedersen, T. Aristotle's Theory of Moral Insight. Oxford: Oxford University Press 1983.

Gadamer, Hans-Georg. Truth and Method. Second, revised edition. New York: The Crossroad Publishing Company 1990.

Garver, Eugene. 'The Moral Virtues and the Two Sides of Energeia', Ancient Philosophy 9 (1989) 293-312.

Greenwood, L.H.G. Aristotle, Nicomachean Ethics, Book Six. Cambridge: Cambridge University Press 1909; Arno repr. 1973.

Irwin, Terence. 'First Principles in Aristotle's Ethics', Midwest Studies in Philosophy 3(1978) 252-72.

Irwin, Terence. 'Aristotle's Conception of Morality', Proceedings of the Boston Area Colloquium in Ancient Philosophy 1 (1985a) 115-43.

Irwin, Terence. Aristotle. Nicomachean Ethics. Indianapolis: Hackett Publishing Company $1985 \mathrm{~b}$.

Joachim, H.H. Aristotle. The Nicomachean Ethics, ed. D.A. Rees. Oxford: Oxford University Press 1951.

Kenny, Anthony. The Aristotelian Ethics. Oxford: Oxford University Press 1978. 
Keyt, David. 'Intellectualism in Aristotle', Paideia. Special Aristotle Issue 1978.

Kraut, Richard. Aristotle on the Human Good. Princeton, NJ: Princeton University Press 1989.

Louden, Robert B. 'Aristotle's Practical Particularism', Ancient Philosophy 6 (1986) 123-38, reprinted in John P. Anton and Anthony Preus, eds., Essays in Ancient Greek Philosophy IV: Aristotle's Ethics. Albany: State University of New York Press 1991, 159-78. Cited from reprint.

MacDowell, John. 'Virtue and Reason', Monist 62 (1979) 330-50.

Mingay, J., ed. Aristotelis Ethica Eudemia. Oxford: Oxford University Press 1991.

Nussbaum, Martha Craven. Aristotle's De Motu Animalium. Princeton, NJ: Princeton University Press 1978.

Nussbaum, Martha Craven. The Fragility of Goodness. Cambridge: Cambridge University Press 1986.

Nussbaum, Martha Craven. 'Non-Relative Virtues: An Aristotelian Approach', Midwest Studies in Philosophy 13 (1988) 32-53.

Peterson, Sandra. 'Horos [Limit] in Aristotle's Nicomachean Ethics', Phronesis 33 (1988) 233-50.

Peterson, Sandra. 'Apparent Circularity in Aristotle's Account of Right Action in the Nicomachean Ethics', Apeiron 25 (1992) 83-107.

Reeve, C.D.C. Practices of Reason. Aristotle's Nicomachean Ethics. Oxford: Oxford University Press 1992.

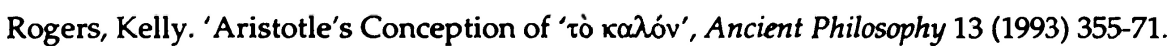

Ross, W.D. Aristotle, fifth edition. London: Methuen 1949.

Rowe, C.J. The Eudemian and Nicomachean Ethics: $A$ Study in the Development of Aristotle's Thought. Cambridge: Cambridge University Press 1971.

Sherman, Nancy. The Fabric of Character. Oxford: Oxford University Press 1988.

Shiner, R.A. 'Aisthêsis, Nous and Phronésis in the Practical Syllogism', Philosophical Studies 36 (1979) 377-87.

Sparshott, Francis. Taking Life Seriously. A Study of the Argument of the Nicomachean Ethics. Toronto: University of Toronto Press 1994.

Stocks, J.L. 'On the Aristotelian Use of $\lambda$ ópos: A Reply' Classical Quarterly 8 (1914) 9-12.

Tuozzo, T.M. 'Conceptualized and Unconceptualized Desire in Aristotle', Journal of the History of Philosophy 32 (1994) 525-49.

Tuozzo, T.M. 'Aristotle's Theory of the Good and Its Causal Basis', Phronesis 40 (1995) 293-314.

Verdenius, W.J. 'Human Reason and God in the Eudemian Ethics' in P. Moraux and D. Harlfinger, eds., Untersuchungen zur Eudemischen Ethik. Berlin: De Gruyter 1971, 285-97. 


\section{Thomas M. Tuozzo}

White, Stephen A. Sovereign Virtue: Aristotle on the Relation between Happiness and Prosperity. Stanford: Stanford University Press 1992.

Woods, M. 'Intuition and Perception in Aristotle's Ethics', Oxford Studies in Ancient Philosophy 4 (1986) 145-66.

Woods, M. Aristotle's Eudemian Ethics Book I, II, and VIII, second edition. Oxford: Oxford University Press 1992. 